\title{
The Effect of Positive Psychology Interventions on Hope and Well-being of Adolescents Living in a Child and Youth Care Centre
}

Krysia Teodorczuk ${ }^{1}$, Tharina Guse ${ }^{* 2}$, and Graham du Plessis ${ }^{1}$

${ }^{1}$ Department of Psychology, University of Johannesburg, Johannesburg, South Africa ${ }^{2}$ Department of Psychology, University of Pretoria, Pretoria, South Africa

*Corresponding Author

Tharina Guse

Department of Psychology

University of Pretoria

Private Bag X20

Hatfield 0028

tharina.guse@up.ac.za 


\begin{abstract}
This study evaluated the effect of positive psychology interventions (PPIs) on hope and well-being among adolescents living in a child and youth care centre (CYCC) in South Africa. Adolescents $(n=29)$ were allocated to either the experimental or control group through matched sampling. The experimental group engaged in one-hour intervention sessions weekly for six weeks. Measures of well-being and hope were recorded at three time intervals. Independent- and paired-sample t-tests were conducted to establish group differences. There were no statistically significant differences in well-being and hope between the two groups after the interventions. We discuss moderating factors and offer a qualitative reflection to better understand these outcomes. With this understanding, preliminary guidelines are proposed for implementing PPIs in CYCCs.
\end{abstract}

Keywords: Vulnerable adolescents, looked-after youth, child and youth care centres, residential care, positive psychology interventions, well-being, hope. 
Adolescence is a transitional period of life involving rapid physical, biological, cognitive, and psychosocial development (Berger, 2011; Santrock, 2010). These substantial changes contribute towards a notoriously tumultuous and challenging decade of life (Santrock, 2010). Adolescents living in Child and Youth Care Centres (CYCCs) experience stressors beyond those of their family-nurtured peers. Because of a history of complex and frequently maladaptive home, school, and social environments, these youths are vulnerable to increased developmental challenges and psychological malady.

Research has repeatedly revealed significantly higher levels of psychopathology (Kjelsberg \& Nygren, 2004; Richardson \& Lelliott, 2003) and lower levels of well-being (Leslie, Gordon, Ganger, \& Gist, 2002; Zimmer \& Panko, 2006) among residents of youth care facilities when compared to their family-nurtured peers. Moreover, these vulnerable youths are also prone to low levels of self-worth, self-esteem, and hope towards positive outcomes for their future (Aguilar-Vafaie, Roshani, Hassanabadi, Masoudian, \& Afruz, 2011; Milkman \& Wanberg, 2012). In combination, increased psychopathology, reduced wellbeing, and low levels of hope reduce vulnerable youths' prognosis for optimal functioning.

Traditionally, research on mental health of youths in general and more specifically vulnerable youths focussed almost exclusively on psychological disorder (Evans et al., 2005). However, interventions associated with this framework gave no attention to individuals' positive attributes or strengths (Seligman, 2002; Seligman \& Csikszentmihalyi, 2000). Yet, it is equally important to promote mental health and to encourage optimal functioning through a focus on that which is positive, adaptive, and whole (Peterson \& Seligman, 2004). Interventions grounded in positive psychology offer a manner in which to support and enhance positive growth through identification, utilisation, and cultivation of psychological strengths, and thus present a means to enable and empower young people. 
Further, due to the maturation of cognitive capacities, adolescence offers a timeous opportunity to introduce tools and exercises that may promote growth, cultivate strengths, and enhance well-being even in the presence of vulnerability. It is therefore valuable to implement and evaluate positive interventions among youth living in CYCC's.

The social contexts within which adolescents grow up play an important role in their development. These environments and the associated circumstances contribute towards protective and risk factors that promote or hinder the transition to adulthood. In particular, poverty, long-term family disadvantage, domestic violence and abuse, maltreatment, neglect and abandonment, as well as multiple placements in out of home facilities, and lack of family contact are among established risk factors known to predict negative outcomes for developing adolescents (Berger, 2011; Cluver \& Gardner, 2007; Coleman \& Hagell, 2007).

The high occurrence of individual, family, and community risk factors that impact on looked-after adolescents, place them at high risk for a poor prognosis involving social, psychological, and behavioural problems culminating in restricted life opportunities (Coleman \& Hagell, 2007; Fergusson \& Horwood, 2003). However, some individuals display remarkable resilience and despite their exposure to major adversity, appear to cope well and adapt positively. These resilient youths are able to draw from various resources that may assist them to resist significant stress, trauma, and adversity. The reservoir of resources, including individual, family, and community attributes are referred to as protective factors (Aguilar-Vafaie et al., 2011; Coleman \& Hagell, 2007).

Research focussed on optimal youth development draws the distinction between protective factors at an individual level as well as those at a social-contextual level that include family and community attributes (Aguilar-Vafaie et al., 2011; Coleman \& Hagell, 2007). Cluver and Gardner (2007) indicated that little research has been done regarding protective factors among looked-after adolescents in the South African context. However, 
they reported that familial and social protective factors including pro-social peer relationships, and positive activities including sport, dancing, and reading were associated with lower levels of anxiety and depression. International research has identified individual protective factors in at-risk children including attributes such as hope (Hagen, Myers, \& Mackintosh, 2005; Herth, 1998), positive views of the self (Cicchetti, 2010; Coleman \& Hagell, 2007; Daniel, Wassell, \& Gilligan, 1999; Fergusson \& Horwood, 2003), goal-setting and achievement orientation (Cicchetti, 2010; Coleman \& Hagell, 2007), pro-social values, relationships, and behaviours (Aguilar-Vafaie et al., 2011; Cicchetti, 2010; Daniel et al., 1999; Milkman \& Wanberg, 2012; Mullan \& Fitzsimons, 2006), the development of skills (Coleman \& Hagell, 2007; Mullan \& Fitzsimons, 2006), as well as identification and use of character strengths (Moore, 2010; Park, 2004). Enhancing these attributes may serve to buffer vulnerable youth against stressful and negative life circumstances.

One way to enhance such positive attributes is through implementing positive psychology interventions (PPIs). PPIs are intentional activities aimed to cultivate positive emotions, cognitions, or behaviours (Sin \& Lyubomirsky, 2009). These interventions are usually brief and easy to implement, yet are theory-informed and evidence based (Parks \& Biswas-Diener, 2013). In this study, we selected PPIs that aimed to identify and build character strengths, and to cultivate positive emotions and hope.

Character strength interventions are based on the premise that developing individuals' strengths rather than focussing on their weaknesses may produce greater benefits (Quinlan, Swain, \& Vella-Brodrick, 2012). Character strengths are positive traits reflected in an individual's thoughts, feelings, and behaviours (Park, Peterson \& Seligman 2004). Engaging one's character strengths allows individuals to achieve optimal functioning while pursuing valued endeavours. As such, character strengths act as protective factors that buffer 
youths against adverse life circumstances, and also support and enhance well-being (Quinlan, et al., 2012).

The maladaptive home and social environments from which adolescents residing in CYCCs hail, often lack support and guidance, inhibiting them from identifying and developing character strengths (Epstein, 2000). Research has shown that identifying, planning to develop, using, and building character strengths may increase well-being and alleviate depression (Gander, Proyer, Ruch, \& Wyss, 2012; Proctor et al., 2011; Seligman, Steen, Park, \& Peterson, 2005). Therefore, it is important to give these youths a general understanding of character strengths, and provide them the opportunity to identify, utilise, and cultivate their strengths. Strengths-based interventions include 'you at your best' (Seligman et al., 2005), 'strength spotting' (Proctor et al., 2011), and 'using character strengths in a new way' (Seligman et al., 2005).

Activities that generate positive emotions give rise to an upward spiral of positive emotions, open up new possibilities, potentially broaden behaviour, and build psychological resources (Fredrickson, 2001). Gratitude activities can be good starter exercises to facilitate the experience of positive emotions (Layous, Lee, Choi, \& Lyubomirsky, 2013). Research indicated that gratitude interventions enhance well-being, life satisfaction, and optimism as well as reduce negative affect and lower levels of depression and anxiety (Emmons \& McCullough, 2003; Froh, Sick, \& Emmons, 2008; Seligman et al., 2005).

Engaging in positive aspects of the present moment can also induce an upward spiral of emotions that ultimately enriches life through enhancing well-being while presenting opportunity to thrive (Guse, 2014). Doing acts of kindness, savouring, and loving-kindness meditation (LKM) are activities that focus on enhancing positive emotions in the present moment. Evidence suggests that pro-social activity, including acts of kindness, may buffer vulnerable adolescents from engaging in disruptive and problem behaviours (Milkman \& 
Wanberg, 2012). Further, such altruistic behaviour may serve to build resilience, self-respect, and hopefulness, which may protect vulnerable youths against feelings of defeat and despair. Additionally, these well-intended behaviours can enhance social relationships and increase well-being (Guse, 2014; Suldo \& Michalowski, 2007).

Savouring is a process through which people "attend to, appreciate, and enhance the positive experiences in their lives" (Bryant \& Veroff, 2007, p. 2). Immersion in favourable experiences strengthens awareness of the positive and pleasurable, which simultaneously reduces negativity bias and defends against negative emotions (Suldo \& Michalowski, 2007). Intervention studies implementing savouring exercises reported positive correlations with well-being (Bryant, Smart, \& King, 2005; Jose, Lim, \& Bryant, 2012) self-esteem, positive affect, and life satisfaction (Cafasso, 1994, 1998), as well as negative correlations with negative affect and depressive symptoms (Cafasso, 1994, 1998; Hurley \& Kwon, 2012).

Like savouring, LKM also offers opportunity for enhancing positive emotions in the present moment. This meditative practice has its origins in Buddhist traditions of emphasizing and cultivating connectedness, whilst expressing positive and loving intentions towards others (Hutcherson, Seppala, \& Gross, 2008). Studies that implemented LKM in the context of social and interpersonal relationships demonstrated enhanced positive affect, compassion, and empathy, promoted optimism, and reduced negative affect (Fredrickson, Cohn, Coffey, Pek, \& Finkel, 2008; Garland et al., 2010; Hutcherson et al., 2008; Kristeller \& Johnson, 2005).

Hope-based interventions focus on generating positive future expectations. Increasing levels of hope through specific activities may enhance well-being, positive affect, and goaldirected activity whilst reducing symptoms of depression and anxiety (Cheavens, Feldman, Gum, Michael, \& Snyder, 2006; King, 2001; Feldman \& Dreher, 2012; Layous, Nelson, \& Lyubomirsky, 2012; Marques, Lopez, \& Pais-Ribeiro, 2011). Additionally, enhanced levels 
of hope may serve to buffer individuals against negative and stressful life events (Suldo \& Michalowski, 2007).

Hope-based interventions have mostly conceptualised hope as a cognitivemotivational construct, as put forward by Snyder et al. (2003). "The best possible future self' (King, 2001) and 'goal mapping' (Feldman \& Dreher, 2012) have been implemented successfully in adult, adolescent and child populations.

Against this backdrop, the aim of our study was to implement and evaluate the effect of a series of PPIs on the well-being and hope of a group of adolescents living in a CYCC. We conceptualised well-being broadly in terms of Keyes' (2005) complete model of mental health, evaluating both the presence of positive mental health and the absence of depression and anxiety. Additionally, we viewed hope in cognitive-motivational terms, as described by Snyder et al. (2003). We expected that the PPIs would increase well-being and hope in this vulnerable population, whilst also decreasing depression and anxiety.

\section{Method}

\section{Design}

We implemented a non-randomised, quasi-experimental design. Due to the small sample size, we implemented non-random assignment to the experimental or control group. A matched-groups design was employed to control for potential selection effects (Morling, 2012). In order to mitigate potential third variable influences regarding age, gender, and ethnicity, participants were allotted to the experimental or control group in as parsimonious a match as possible (Wilson \& MacLean, 2011). 


\section{Participants}

The sample comprised of 29 adolescents within a single care facility according to availability and accessibility. Their ages ranged between 14 and 18 years $(M=16.31 ; S D=1.37)$. The majority of the sample were female (59\%) and of African ethnicity $(62 \%)$.

\section{Procedure}

The intervention was implemented by the first author and consisted of six structured, onehour sessions conducted over a six-week period. The programme drew from research and interventions conducted by, among others, Suldo and Michalowski (2007), Proctor et al. (2011), and Feldman and Dreher (2012). Specific activities included counting blessings, engaging in acts of kindness, as well as identifying and using character strengths. To enhance hope, the 'best possible self' (King, 2001) and goal mapping (Feldman \& Dreher, 2012) exercises were implemented. In addition to these exercises, LKM and a savouring exercise were practiced in each session.

All but the first intervention session opened with a recapitulation of the previous week's intervention and a reflection on homework exercises, if given (e.g. to continue counting blessings). The week's review was followed by a brief savouring exercise to facilitate focussing the group's attention to the present moment. Thereafter, group discussions centred on the specific topic (e.g. gratitude) took place. These discussions were followed by an activity associated with the topic of discussion. Each session closed with a five-minute

\section{LKM.}

The two groups completed measures of well-being and hope before the study commenced, and again at one week after conclusion of the intervention. Another follow-up measure was included five weeks later. The control group received the same intervention after collection of all data. 


\section{Ethical considerations}

The Faculty of Humanities Research Ethics Committee provided ethical approval to conduct the research. The participating CYCC's Childcare Services Manager also provided permission to conduct the study. Further to this, the Childcare Services Manager acted as guardian to provide informed consent for each participant. Additionally, the participants provided assent to partake in the intervention. They were advised that all information provided would remain anonymous and confidential, that the study was not compulsory, and that they were allowed to withdraw from the programme at any time without any consequences.

In accordance with the principle of beneficence, every effort and intention was made to provide benefit to the adolescents involved in the study, moreover each exercise and group session was considered with the core focus of doing no intentional or unintentional harm to the participants of the study.

\section{Measures}

Mental Health Continuum Short Form (MHC-SF; Keyes, 2009)

The MHC-SF measures positive mental health and consists of 14 items, comprising a threefactor structure measuring emotional, psychological, and social well-being, yielding a total well-being score. Using a six-point Likert scale, the participants are asked to rate the frequency with which they experienced symptoms of positive mental health over the past month. Multiple studies have evidenced the MHC-SF to show high internal consistency ( $\alpha>$ .80) among adults and adolescents (Keyes, 2005, 2006, 2009; Keyes et al., 2008, Westerhof $\&$ Keyes, 2010). Cronbah's alpha was also high in our study $(\alpha=86)$. 
The CHS is a 6-item self-report questionnaire assessing dispositional hope among young people aged 8 to 16 years. The six items are divided equally to measure the bi-faceted construct of hope; the odd numbered items represent agentic thought, while the even numbered items represent pathways thinking. The CHS is hand-scored on a 6-point Likert scale, with total scores ranging between 6 (reflecting low levels of hope) and 36 (indicating high levels of hope). Snyder et al. (1997) reported that the CHS showed temporal stability, and established convergent, discriminant, predictive, and incremental validity. The CHS also evidenced satisfactory psychometric properties among South African adolescents (Guse, de Bruin \& Kok, 2016). In our study, Cronbach's alpha was .71.

\section{Revised Child Anxiety and Depression Scale - Short Version (RCADS-SV; Ebesutani et al., 2012)}

The 25-item RCADS-SV is a brief measure of symptoms specific to pathological anxiety and depressive disorders in children and adolescents. The self-report questionnaire is scored on a 4-point Likert scale, and is normed according to gender and grade level. Research revealed good internal consistency, with the anxiety subscale yielding Cronbach's alpha coefficients of .86 and .91 in non-referred and clinical samples, respectively. The depression subscale advanced Cronbach's alpha coefficients of .79 in the non-referred sample and .80 in the clinical sample. Additionally, good convergent and divergent, as well as acceptable concurrent validity were established with clinical diagnostic groups (Ebesutani et al., 2012). In the current study the internal consistency of the RCAFS-SV was $\alpha=.86$.

\section{Data analysis}

We employed descriptive statistics for the scale scores and demographics of the sample. The means of the dependent variables within and between the control and experimental groups 
before, as well as one and five weeks after the intervention were compared using independent-samples $t$-tests (for between group comparisons) and paired-samples $t$-tests (for within group comparisons). Parametric assumptions were tested beforehand in order to determine the appropriate tests of difference.

\section{Results}

The results of between and within group analysis are presented in Tables 1 and 2 respectively. The baseline measures indicated that there were no statistically significant differences between the two groups on all measures before the intervention (Table 1). After the intervention, there was a slight decrease in hope in the experimental group and a marginal increase in the control group. However, these differences were not statistically significant. At the five-week follow-up, there were no statistically significant differences in levels of hope between the two groups. Likewise, measures of the presence of positive functioning (MHCSF) and absence of psychopathology (RCADS-SV) yielded no significant differences between the experimental and control groups one and five weeks after the intervention. 
Table 1. Differences between experimental and control groups pre, post, and follow-up

\begin{tabular}{lllllll}
\hline & & \multicolumn{2}{c}{ Experimental Group } & \multicolumn{2}{c}{ Control Group } \\
\cline { 3 - 6 } & & Mean & $S D$ & Mean & $S D$ & $p$ \\
\cline { 3 - 6 } CHS & Pre-Test & 25.86 & 5.57 & 21.87 & 5.81 & .70 \\
& Post-Test & 22.50 & 5.29 & 24.07 & 5.12 & .42 \\
& Follow-Up & 24.14 & 4.98 & 22.40 & 6.22 & .41 \\
\hline \multirow{2}{*}{ MHC-SF } & Pre-Test & 48.43 & 12.68 & 47.07 & 9.35 & .74 \\
& Post-Test & 48.21 & 11.81 & 47.60 & 8.39 & .87 \\
& Follow-Up & 48.71 & 14.71 & 43.80 & 14.53 & .37 \\
\hline \multirow{2}{*}{ RCADS-SV } & Pre-Test & 60.36 & 12.45 & 55.67 & 9.06 & .25 \\
& Post-Test & 56.71 & 13.36 & 54.93 & 10.74 & .70 \\
& Follow-Up & 55.29 & 11.53 & 58.07 & 18.15 & .63 \\
\hline
\end{tabular}

Note: MHC-SF = Mental Health Continuum - Short Form; RCADS-SV = Revised Child Anxiety and Depression Scale - Short Version.

Within-group comparisons also showed no statistically significant changes in well-being and hope before and after the intervention, as reflected in Table 2. Although the experimental group scores showed a downward trend in depression and anxiety after the intervention, these results were not statistically significant when compared to baseline scores. 
Table 2. Differences within the experimental and control groups pre, post, and follow-up

\begin{tabular}{lllllllllll}
\hline & & \multicolumn{2}{c}{ Pre-Test } & \multicolumn{2}{c}{ Post-Test } & \multicolumn{4}{c}{ Follow-Up } \\
\cline { 3 - 11 } & & & Mean & $S D$ & Mean & $S D$ & $p$ & Mean & $S D$ & $p$ \\
\hline \multirow{2}{*}{ Experiment } & CHS & 25.86 & 5.57 & 22.5 & 5.29 & .04 & 24.14 & 4.98 & .22 \\
& MHC-SF & 48.43 & 12.68 & 48.21 & 11.81 & .95 & 48.71 & 14.72 & .94 \\
& RCADS-SV & 60.36 & 12.45 & 56.71 & 13.36 & .29 & 55.29 & 11.53 & .19 \\
\hline \multirow{2}{*}{ Control } & CHS & 21.87 & 5.81 & 24.07 & 5.12 & .05 & 22.4 & 6.22 & .65 \\
& MHC-SF & 47.07 & 9.35 & 47.60 & 8.39 & .80 & 43.80 & 14.53 & .24 \\
& RCADS-SV & 55.67 & 9.06 & 54.93 & 10.74 & .77 & 58.07 & 18.15 & .53 \\
\hline
\end{tabular}

Note: MHC-SF = Mental Health Continuum - Short Form; RCADS-SV = Revised Child Anxiety and Depression Scale - Short Version.

\section{Discussion}

The aim of our study was to examine the effect of a series of PPIs on well-being and hope of a group of adolescents living in a CYCC. Contrary to our expectations, the intervention did not lead to increased well-being or hope, nor was there a reduction in their levels of anxiety and depression. Our findings are similar to a few studies indicating that PPIs may not lead to improvements in well-being (Dickens, 2017; Marques et al., 2011) and hope (Weiss \& Speridakos, 2011) among youth, yet published research on non-significant findings of the effect of PPIs remain scarce. To gain better understanding of these outcomes, we considered baseline levels of well-being and hope as well as moderating factors that may have contributed to the non-significant findings. We also offer a qualitative reflection on implementing PPIs.

The mean scores obtained on measures of well-being and hope were, surprisingly, comparable to, and generally better than those of referred and non-referred peer populations reported on in previous studies (see Gilman, Dooley, \& Florell, 2006; Guse \& Vermaak, 2011; McNeal et al., 2006; Snyder et al., 1997; van Schalkwyk \& Wissing, 2010). This 
indicates that our sample evidenced higher levels of well-being and hope than expected. It is therefore possible that, with limited scope for improvement on subsequent measures, the ceiling effect could have contributed towards the non-significant outcomes of this study (Goodwin, 2010). Still, this explanation should be viewed with caution, as the objective reality of these youth may not warrant such high levels of well-being. However, a recent study among children in disadvantaged areas in the Western Cape, South Africa, also reported relatively high levels of subjective well-being (Savahl et al. 2015). It is evident that more research is needed regarding the measurement, experience and dynamics of well-being among South African children and adolescents.

Methodological and participatory moderators may also have played a role in the efficacy of the intervention. Nations and cultures may well differ in orientations of happiness, Park, Peterson, and Ruch (2009) reported that South Africans scored the highest out of 27 nations on an orientation towards pleasure. Thus, the MHC-SF, which largely incorporates elements of meaning and engagement in life, may not have fully tapped into the more transient, malleable, and affect based facets of well-being, which may be relevant to this particular sample. Another methodological moderator that deserves mention is that of the duration of the intervention. In their meta-analysis of 51 interventions, Sin and Lyubomirsky (2009) reported that interventions of longer durations produced larger gains in well-being. The current study's six-week intervention fell within the second shortest of four temporal categories described in the meta-analysis. Therefore increasing the duration of the intervention may have yielded results of significance.

In addition to methodological moderators, research has repeatedly indicated individuals' behaviours, circumstances, and characteristics may contribute to the efficacy of interventions. According to Lyubomirsky and colleagues (Lyubomirsky, Dickerhoof, Boehm, \& Sheldon, 2011; Sin, Della Porta, \& Lyubomirsky, 2011; Sin \& Lyubomirsky, 2009), 
studies that recruited participants, as opposed to self-selection studies, yielded weaker and less robust effects. These scholars suggested that self-selection, driven by conscious knowledge of the purpose of interventions, was associated with motivation to achieve proposed outcomes. As such, motivation and increased effort placed on completing exercises, in combination with positive expectations, may have contributed towards stronger and more durable outcomes. Although participation in the current study was voluntary, adolescents did not personally pursue the programme, nor were they made aware of the aim to enhance levels of well-being and hope. As such, participants may have lacked motivation and effort in completing tasks.

Researchers have suggested that engaging in positive activities yields better results when those performing tasks receive social support and encouragement (Layous, Sheldon, \& Lyubomirsky, 2014; Lyubomirsky et al., 2011, Sin et al., 2011). Research has indicated that children in care facilities experienced less emotional and social support than their familynurtured counterparts (Allen \& Vacca, 2010). Additionally, negative peer appraisals, increased loneliness, fewer friendships, and less satisfaction within relationships are factors associated with cared-for youths (Dinisman, Montserrat, \& Casas, 2012). It may therefore be possible that the vulnerable population in this study could have experienced lower levels of support, involvement, reassurance, and encouragement when performing PPI exercises, which may have played a role in the effectiveness of the PPI.

Frequency and variation of practiced activities could impact on the effectiveness of gratitude and kindness interventions (Emmons \& McCullough, 2003; Lyubomirsky, Sheldon, \& Schkade, 2005; Sheldon \& Lyubomirsky, 2012; Sheldon, Boehm, \& Lyubomirsky, 2013; Tkach, 2005). Although instructions for these interventions were given in accordance with the findings, it appeared apparent in weekly feedback discussions that neither variety nor timing of tasks were maintained, even with repeated encouragement. Failure to observe task 
instructions may have resulted in participants performing tasks differently than suggested by empirical evidence, thereby contributing to the lack of change in outcome measures.

Research suggests that different positive activities may better suit participants with different personalities, values, strengths, interests, cultural preferences, and circumstances (Lyubomirsky \& Layous; 2013; Nelson \& Lyubomirsky, 2012; Parks, Della Porta, Pierce, Zilca, \& Lyubomirsky, 2012). Higher levels of person-activity fit have been associated with greater benefits (Nelson \& Lyubomirsky, 2012; Schueller, 2011). The current study did not account for individual differences among participants, and therefore may have inadvertently employed activities not best suiting all participants, thus negatively influencing participant engagement and measured outcomes.

The statistically non-significant outcomes of our study may not be a true or complete reflection of the possible benefits of the intervention. Qualitatively we observed improvement in communication, confidence, self-esteem, positive affect, and future-focussed optimism among some participants. Identifying and building character strengths noticeably enhanced levels of self-confidence and self-worth in a number of adolescents, with one participant privately reporting the impact these exercises had on assertiveness, self-belief, and self-value. Additionally, several adolescents reported that practicing gratitude made them more aware of how much they had, as opposed to focussing on what was missing in their lives. Individuals mentioned that this practice, although 'obvious', was not within their regular behaviour, and one went so far as to be grateful for the gratitude exercise, whilst another stated gratitude towards the intervention programme.

Youths also reflected positively on the weekly savouring activity, expressing gratitude for the immediate experience of indulgence as well as for their newfound capacity of identifying novel ways of appreciating regular experiences. Engaging in LKM reportedly brought calm into their otherwise hectic lives. A few adolescents remarked that LKM brought 
them a sense of connectedness and warmth with the prospect of offering anonymous help to others where they felt otherwise helpless.

Although participants seemed to enjoy the 'acts of kindness' and 'best possible future self' exercises on the whole, both activities generated a negative response in a few individuals. First, three members of the experimental group mentioned disliking performing acts of kindness as they found people either ridiculed them for their kind efforts or took advantage of their kindness. On the other hand, others expressed pleasure in performing kind acts, stating that the intrinsic reward of practicing kindness far outweighed the effort spent on the practice. Second, during the 'best possible future self' exercise, one individual was reluctant to generate such an image to avoid the inevitable sadness of disappointment. According to this participant, not creating positive expectations was a protective mechanism developed following 'a life of bad experiences'. On the other hand, several adolescents in our study expressed vivid visualisations of seemingly achievable and desirable 'best possible future self' images, once again exhibiting complete immersion and belief in the activity and in themselves. Finally, it was encouraging that a particularly troubled participant from the experimental group voluntarily attended the control group sessions as well, thereby experiencing the PPI for a second time. Additionally, an adolescent not involved in the study, and another who had declined consenting to participation, requested permission to attend the control group intervention, which attests to favourable reports from participants in the experimental group.

The subtleties in positive behavioural and attitudinal changes noted, as well as information regarding the benefits and drawbacks of specific activities implemented were not identified or assessed through the quantitative study. Including a qualitative component in future research on PPIs may therefore yield valuable information. Taking into account the elements discussed above, and the possible benefits vulnerable adolescents may gain from 
these activities, brief guidelines are offered for the implementation of PPIs among cared-for youth.

\section{Future considerations for implementing PPIs in CYCCs}

Considering that intervention duration moderates the effectiveness of PPIs with significantly greater benefit associated with longer treatments (Sin \& Lyubomirsky, 2009), we suggest that PPIs longer than 8 weeks be implemented. Such practice may better support skill improvement and provide opportunity for rehearsed positive activities to develop into habitual practices.

Where possible, intended intervention outcomes should be transparent, providing youths with explicit motive and intrinsic incentive to fully immerse themselves in effortful practice of positive activities. Additionally, activities should be adapted to accommodate person-activity fit. For example, where acts of kindness may be better suited to more socially extroverted participants (Nelson \& Lyubomirsky, 2012), youths in the current study who expressed discomfort with this exercise may have benefitted more by practicing selfcompassion.

Bearing in mind the premise that expressing gratitude gives rise to an upward spiral of positive emotions, and that the participants seemed to enjoy the gratitude exercise, we suggest that exploring the virtue of gratitude, identifying blessings rather than burdens, and expressing appreciation for these blessings be the focus of the initial session. Similarly, participants provided positive feedback on engaging in LKM and savouring. It seems that these two activities served to focus the group's attention while simultaneously enhancing positive emotions in the present moment. We recommend that these exercises be repeated regularly throughout a PPI. 
Finally, the PPIs included in this study were selected with specific focus on, and consideration of the characteristics, risk factors, and vulnerabilities of adolescents residing in CYCCs. Based on our qualitative observations, PPIs aimed at optimising mental health and enhancing levels of well-being and hope in this population could include at least some of the activities implemented in this study.

In conclusion, despite the fact that our study did not find a significant improvement in well-being and hope for adolescents participating in a PPI, we expanded emerging literature that cautions against the over-optimistic implementation of positive interventions among youth. Qualitatively, however, there appeared to be value in these positive interventions for the adolescents in our sample and we encourage further mixed-method research on PPIs among vulnerable youth. 
References

Aguilar-Vafaie, M. E., Roshani, M., Hassanabadi, H., Masoudian, Z., \& Afruz, G. A. (2011). Risk and protective factors for residential foster care adolescents. Children and Youth Services Review, 33(1), 1-15. doi:10.1016/j.childyouth.2010.08.005

Allen, B., \& Vacca, J. S. (2010). Frequent moving has a negative affect on the school achievement of foster children makes the case for reform. Children and Youth Services Review, 32(6), 829-832. doi:10.1016/j.childyouth.2010.02.001

Berger, K. S. (2011). The developing person through the lifespan ( $8^{\text {th }}$ ed.). New York, NY: Worth.

Bryant, F. B., Smart, C. M., \& King, S. P. (2005). Using the past to enhance the present: Boosting happiness through positive reminiscence. Journal of Happiness Studies, 6(3), 227-260. doi:10.1007/s10902-005-3889-4

Bryant, F. B., \& Veroff, J. (2007). Savoring: A new model of positive experience. Mahwah, NJ: Lawrence Erlbaum.

Cafasso, L. L. (1994). Uplifts and hassles in the lives of young adolescents. (Unpublished master's thesis). Loyola University Chicago, Chicago.

Cafasso, L. L. (1998). Subjective well-being of inner-city resilient and non-resilient young adolescents. (Unpublished doctoral dissertation). Loyola University Chicago, Chicago.

Cheavens, J. S., Feldman, D. B., Gum, A., Michael, S. T., \& Snyder, C. R. (2006). Hope therapy in a community sample: A pilot investigation. Social Indicators Research, $77(1), 61-78$.

Cicchetti, D. (2010). Resilience under conditions of extreme stress: A multilevel perspective. World Psychiatry: Official Journal of the World Psychiatric Association (WPA), 9(3), $145-54$.

Cluver, L., \& Gardner, F. (2007). Risk and protective factors for psychological well-being of children orphaned by AIDS in Cape Town: A qualitative study of children and caregivers' perspectives. AIDS Care, 19(3), 318-25. doi:10.1080/09540120600986578

Coleman, J., \& Hagell, A. (2007). Adolescence, risk and resilience: Against the odds. Chichester, UK: John Wiley. 
Daniel, B., Wassell, S., \& Gilligan, R. (1999). “It’s just common sense isn’t it?': Exploring ways of putting the theory of resilience into action. Adoption \& Fostering, 23(3), 6 15. doi:10.1177/030857599902300303

Dickens, L. R. (2017). Using Gratitude to Promote Positive Change: A Series of MetaAnalyses Investigating the Effectiveness of Gratitude Interventions. Basic and Applied Social Psychology, 39(4), 193-208.

Dinisman, T., Montserrat, C., \& Casas, F. (2012). The subjective well-being of Spanish adolescents: Variations according to different living arrangements. Children and Youth Services Review, 34(12), 2374-2380. doi:10.1016/j.childyouth.2012.09.005

Ebesutani, C., Reise, S. P., Chorpita, B. F., Ale, C., Regan, J., Young, J., .. Weisz, J. R. (2012). The Revised Child Anxiety and Depression Scale-Short Version: Scale reduction via exploratory bifactor modeling of the broad anxiety factor. Psychological Assessment, 24(4), 833-45. doi:10.1037/a0027283

Emmons, R. A., \& McCullough, M. E. (2003). Counting blessings versus burdens: An experimental investigation of gratitude and subjective well-being in daily life. Journal of Personality and Social Psychology, 84(2), 377-389. doi:10.1037/00223514.84.2.377

Epstein, M. H. (2000). The behavioral and emotional rating scale: A strength-based approach to assessment. Assessment for Effective Intervention, 25(3), 249-256. doi:10.1177/073724770002500304

Evans, D. L., Foa, E. B., Gur, R. E., Hendin, R., O'Brien, C. P., Seligman, M. E. P., \& Walsh, B. T. (Eds.). (2005). Treating and preventing adolescent mental health disorders: What we know and what we don't know. A research agenda for improving the mental health of our youth. New York, NY: Oxford University Press.

Feldman, D. B., \& Dreher, D. E. (2012). Can hope be changed in 90 minutes? Testing the efficacy of a single-session goal-pursuit intervention for college students. Journal of Happiness Studies, 13(4), 745-759. doi:10.1007/s10902-011-9292-4

Fergusson, D. M. \&Horwood, L. J. (2003). Resilience to childhood adversity: Results of a 21-year study. In: S. S. Luthar (Eds), Resilience and vulnerablity: Adaptation in the context of childhood adversities (pp. 130-155). Cambridge, UK: Cambridge University Press.

Fredrickson, B. L. (2001). The role of positive emotions in positive psychology. American Psychologist, 56(3), 218-226. 
Fredrickson, B. L., Cohn, M. A., Coffey, K. A., Pek, J., \& Finkel, S. M. (2008). Open hearts build lives: Positive emotions, induced through loving-kindness meditation, build consequential personal resources. Journal of Personality and Social Psychology, 95(5), 1045-1062. doi:10.1037/a0013262

Froh, J. J., Sefick, W. J., \& Emmons, R. A. (2008). Counting blessings in early adolescents: An experimental study of gratitude and subjective well-being. Journal of School Psychology, 46(2), 213-33. doi:10.1016/j.jsp.2007.03.005

Gander, F., Proyer, R., Ruch, W., \& Wyss, T. (2012). Strength-based positive interventions: Further evidence for their potential in enhancing well-being and alleviating depression. Journal of Happiness Studies. doi:10.1007/s10902-012-9380-0

Garland, E. L., Fredrickson, B., Kring, A. M., Johnson, D. P., Meyer, P. S., \& Penn, D. L. (2010). Upward spirals of positive emotions counter downward spirals of negativity: Insights from the broaden-and-build theory and affective neuroscience on the treatment of emotion dysfunctions and deficits in psychopathology. Clinical Psychology Review, 30(7), 849-864. doi:10.1016/j.cpr.2010.03.002

Gilman, R., Dooley, J., \& Florell, D. (2006). Relative levels of hope and their relationship with academic and psychological indicators among adolescents. Journal of Social and Clinical Psychology, 25(2), 166-178

Goodwin, C. J. (2010). Research in Psychology: Methods and Design (6 $6^{\text {th }}$ ed.). Hoboken, NJ: Wiley.

Guse, T. (2014). Activities and programmes to enhance well-being. In M.P. Wissing, J. Potgieter, T. Guse, I. Khumalo, \& L. Nel (Eds.), Towards flourishing: Contextualizing positive psychology. Pretoria, RSA: Van Schaik.

Guse, T., De Bruin, G. P., \& Kok, M. (2016). Validation of the children's hope scale in a sample of South African adolescents. Child Indicators Research, 9(3), 757-770.

Guse, T., \& Vermaak, Y. (2011). Hope, psychosocial well-being and socioeconomic status among a group of South African adolescents. Journal of Psychology in Africa. 21(4), $527-534$.

Herth, K. (1998). Hope as seen through the eyes of homeless children. Journal of Advanced Nursing, 28(5), 1053-62. Retrieved from http://www.ncbi.nlm.nih.gov/pubmed/9840877

Hagen, K. B., Myers, B. J., \& Mackintosh, V. H. (2005). Hope, social support, and behavioral problems in at-risk children. American Journal of Orthopsychiatry, 75(2), 211-219. 
Hurley, D. B., \& Kwon, P. (2012). Results of a study to increase savoring the moment: Differential impact on positive and negative outcomes. Journal of Happiness Studies, 13(4), 579-588.

Hutcherson, C. A., Seppala, E. M., \& Gross, J. J. (2008). Loving-kindness meditation increases social connectedness, Emotion, 8(5), 720-724. doi:10.1037/a0013237

Jose, P. E., Lim, B. T., \& Bryant, F. B. (2012). Does savoring increase happiness? A daily diary study. The Journal of Positive Psychology, 7(3), 176-187.

Keyes, C. L. M. (2005). The subjective well-being of America's youth: Toward a comprehensive assessment. Adolescent and Family Health, 4, 3-11.

Keyes, C. L. M. (2006). Mental Health in adolescence: Is America's youth flourishing? American Journal of Orthopsychiatry, 76(3), 395-402.

Keyes, C. L. M. (2009). Atlanta: Brief description of the mental health continuum short form (MHC-SF). Available: http://www.sociology.emory.edu/ckeyes/. [On-line, retrieved 26 January, 2014].

Keyes, C. L. M., Wissing, M., Potgieter, J. P., Temane, M., Kruger, A., \& van Rooy, S. (2008). Evaluation of the Mental Health Continuum - Short Form (MHC - SF) in Setswana-speaking South Africans. Clinical Psychology and Psychotherapy, 15(3), $181-192$.

King, L. (2001). The health benefits of writing about life goals. Personality and Social Psychology Bulletin, 27(7), 798-807. doi:10.1177/0146167201277003

Kjelsberg, E., \& Nygren, P. (2004). The prevalence of emotional and behavioural problems in institutionalized childcare clients. Nordic Journal of Psychiatry, 58(4), 319-25. doi:10.1080/08039480410005846

Kristeller, J.L., \& Johnson, T. (2005). Cultivating loving kindness: A two-stage model of the effects of meditation on empathy, compassion, and altruism. Zygon Journal of Religion and Science, 40(2), 391-408.

Layous, K., Lee, H., Choi, I., \& Lyubomirsky, S. (2013). Culture matters when designing a successful happiness-increasing activity: A comparison of the United States and South Korea. Journal of Cross-Cultural Psychology, 44, 1294-1303.

Layous, K., Nelson, K. S., \& Lyubomirsky, S. (2012). What is the optimal way to deliver a positive activity intervention? The case of writing about one's best possible selves. Journal of Happiness Studies, 14(2), 635-654. doi:10.1007/s10902-012-9346-2 
Layous, K., Sheldon, K. M., \& Lyubomirsky, S. (2014). The prospects, practices, and prescriptions for the pursuit of happiness. In S. Joseph (Ed.), Positive psychology in practice (2nd ed., pp. 248-273). New York, NY: John Wiley.

Leslie, L. K., Gordon, J. N., Ganger, W., \& Gist, K. (2002). Developmental delay in young children in child welfare by initial placement type. Infant Mental Health Journal, 23(5), 496-516.

Lyubomirsky, S., Dickerhoof, R., Boehm, J. K., \& Sheldon, K. M. (2011). Becoming happier takes both a will and a proper way: An experimental longitudinal intervention to boost well-being. Emotion, 11(2), 391-402. doi:10.1037/a0022575

Lyubomirsky, S., \& Layous, K. (2013). How do simple positive activities increase wellbeing? Current Directions in Psychological Science, 22(1), 57-62. doi:10.1177/0963721412469809

Lyubomirsky, S., Sheldon, K. M., \& Schkade, D. (2005). Pursuing happiness: The architecture of sustainable change. Review of General Psychology, 9(2), 111-131. doi:10.1037/1089-2680.9.2.111

Marques, S. C., Lopez, S. J., \& Pais-Ribeiro, J. (2011). "Building hope for the future": A program to foster strengths in middle-school students. Journal of Happiness Studies, 12(1), 139-152. doi:10.1007/s10902-009-9180-3

McNeal, R., Handwerk, M. L., Field, C. E., Roberts, M. C., Soper, S., Huefner, J. C., \& Ringle, J. L. (2006). Hope as an outcome variable among youths in a residential care setting. The American Journal of Orthopsychiatry, 76(3), 304-11. doi:10.1037/00029432.76.3.304

Milkman, H., \& Wanberg, K. (2012). Adolescent development and pathways to problem behavior. In Criminal conduct and substance abuse treatment for adolescents: Pathways to self-discovery and change (2nd ed., pp. 21-54). Washington, DC: Sage.

Moore, W. (2010). Investigation of character strengths among college attendees with and without a history of child abuse (Unpublished doctoral dissertation). Massachusetts School of Professional Psychology, Massachusetts.

Morling, B. (2012). Research methods in psychology: Evaluating a world of information. New York, NY: W.W. Norton

Mullan, C., \& Fitzsimons, L. (2006). The mental health of looked after children / care leavers in Northern Ireland: A literature review (Research Report). Retrieved from http://www.voypic.org/publications/research-policy-reports 
Nelson, S. K. \& Lyubomirsky, S. (2012). Finding happiness: Tailoring positive activities for optimal well-being benefits. In M. Tugade, M. Shiota, \& L. Kirby (Eds.), Handbook of positive emotions (pp. 275-293). New York, NY: Guilford.

Park, N. (2004). Character strengths and positive youth development. The Annals of the American Academy of Political and Social Science, 591(1), 40-54. doi:10.1177/0002716203260079

Park, N., Peterson, C., \& Ruch, W. (2009). Orientations to happiness and life satisfaction in twenty-seven nations. The Journal of Positive Psychology, 4(4), 273-279. doi:10.1080/17439760902933690

Park, N., Peterson, C., \& Seligman, M. E. (2004). Strengths of character and wellbeing. Journal of Social and Clinical Psychology, 23(5), 603-619.

Parks, A. \& Biswas-Diener, R. (2013). Positive Interventions: Past, present and future. In T. B. Kashdan \& J. Ciarrochi (Eds.), The Context Press mindfulness and acceptance practica series. Mindfulness, acceptance, and positive psychology: The seven foundations of well-being (pp. 140-165). Oakland, CA, US: Context Press/New Harbinger Publications.

Parks, A. C., Della Porta, M. D., Pierce, R. S., Zilca, R., \& Lyubomirsky, S. (2012). Pursuing happiness in everyday life: the characteristics and behaviors of online happiness seekers. Emotion, 12(6), 1222-34. doi:10.1037/a0028587

Peterson, C., \& Seligman, M. E. P. (2004). Character strengths and virtues: A classification and handbook. Washington, DC: American Psychological Association.

Proctor, C., Tsukayama, E., Wood, A. M., Maltby, J., Eades, J., \& Linley, P. A. (2011). Strengths gym: The impact of a character strengths-based intervention on the life satisfaction and well-being of adolescents. The Journal of Positive Psychology, 6(5), 377-388. doi:10.1080/17439760.2011.594079

Quinlan, D., Swain, N., \& Vella-Brodrick, D. A. (2012). Character strengths interventions: Building on what we know for improved outcomes. Journal of Happiness Studies, 13(6), 1145-1163.

Richardson, J., \& Lelliott, P. (2003). Mental health of looked after children. Advances in Psychiatric Treatment, 9(4), 249-256. doi:10.1192/apt.9.4.249

Santrock, J. W. (2010). Adolescence (13 ${ }^{\text {th }}$ ed.). New York, NY: McGraw Hill.

Savahl, S., Adams, S., Isaacs, S., September, R., Hendricks, G., \& Noordien, Z. (2015). Subjective well-being amongst a sample of South African children: A descriptive study. Child Indicators Research, 8(1), 211-226. 
Schueller, S. M. (2011). To each his own well-being boosting intervention: Using preference to guide selection. The Journal of Positive Psychology, 6(4), 300-313.

Seligman, M. E. P. (2002). Positive psychology, positive prevention, and positive therapy. In C. R. Snyder \& S. J. Lopez (Eds.), Handbook of positive psychology (pp. 3-9). Oxford, UK: Oxford University Press.

Seligman, M. E. P., \& Csikszentmihalyi, M. (2000). Positive psychology: An introduction. American Psychologist, 55(1), 5-14.

Seligman, M. E. P., Steen, T. A., Park, N., \& Peterson, C. (2005). Positive psychology progress: Empirical validation of interventions. American Psychologist, 60(5), 410421. doi:10.1037/0003-066X.60.5.410

Sheldon, K. M., Boehm, J. K., \& Lyubomirsky, S. (2013). Variety is the spice of happiness: The hedonic adaptation prevention model. In I. Boniwell \& S. David (Eds.), Oxford handbook of happiness (pp. 901-915). Oxford, UK: Oxford University Press.

Sheldon, K. M., \& Lyubomirsky, S. (2012). The challenge of staying happier: Testing the hedonic adaptation prevention model. Personality and Social Psychology Bulletin, 38, $670-680$.

Sin, N. L., Della Porta, M. D., \& Lyubomirsky, S. (2011). Tailoring positive psychology interventions to treat depressed individuals. In S. I. Donaldson, M. Csikszentmihalyi, \& J. Nakamura (Eds.), Applied positive psychology: Improving everyday life, health, schools, work and society (pp. 79-96). New York, NY: Routledge.

Sin, N. L., \& Lyubomirsky, S. (2009). Enhancing well-being and alleviating depressive symptoms with positive psychology interventions: A practice-friendly meta-analysis. Journal of Clinical Psychology, 65(5), 467-487.

Snyder, C. R., Hoza, B., Pelham, W. E., Rapoff, M., Ware, L., Danovsky, M., ... Stahl, K. (1997). The development and validation of the Children's Hope Scale. Journal of Pediatric Psychology, 22(3), 399-421.

Snyder, C. R., Lopez, S., Shorey, H., Rand, K., \& Feldman, D. (2003). Applying hope theory, measurements, and interventions to school psychology. School Psychology Quarterly, $18,122-13$.

Suldo, S. M., \& Michalowski, J. A. (2007). Subjective well-being intervention program [Procedures manual]. Retrieved from http://www.coedu.usf.edu/schoolpsych/ Faculty/Suldo.html 
Tkach, C. (2005). Unlocking the treasury of human kindness: Enduring improvements in mood, happiness, and self-evaluations (Unpublished doctoral dissertation). University of California, Riverside, CA.

van Schalkwyk, I., \& Wissing, M. P. (2010). Psychosocial well-being in a group of South African adolescents. Journal of Psychology in Africa, 20(1), 53-60.

Weis, R., \& Speridakos, E. C. (2011). A meta-analysis of hope enhancement strategies in clinical and community settings. Psychology of Well-Being, 1(1), 1-16.

Westerhof, G. J., \& Keyes, C. L. M. (2010). Mental illness and mental health: The two continua model across the lifespan, Journal of Adult Development, 17(2), 110-119. doi:10.1007/s10804-009-9082-y

Wilson, S., \& MacLean, R. (2011). Research methods and data analysis for psychology. London, UK: McGraw-Hill.

Zimmer, M. H., \& Panko, L. M. (2006). Developmental status and service use among children in the child welfare system - A national survey. Archives of Pediatrics \& Adolescent Medicine, 160(2), 183-188. 